\title{
Pengaruh Waktu Terhadap Daya Dukung Fondasi Tiang Bersirip Pada Tanah Lunak
}

\author{
Fikri Ananda Putra', Ferry Fatnanta ${ }^{2}$, Agus Ika Putra ${ }^{3}$ \\ 1,2,3Program Studi Teknik Sipil Fakultas Teknik Universitas Riau \\ Kampus Bina Widya KM. 12.5, Pekanbaru, Riau, Telp. (0761) 52324 \\ e-mail: ${ }^{1}$ fikri.ananda@student.unri.ac.id, ${ }^{2}$ fatnanto1964@gmail.com (corresponding author), \\ 3agusip@eng.unri.ac.id
}

\begin{abstract}
Abstrak
Penelitian ini mengkaji tentang pengaruh waktu terhadap peningkatan daya dukung fondasi tiang sirip dan polos. Variasi waktu pengujian dalam penelitian ini adalah 0, 1, 2, 4, 8, 16, 32 dan 64 hari, semua variasi waktu akan di analisis dan membandingkan hasil daya dukung aksial dari fondasi tiang sirip dan polos. Hasil penelitian ini menampilkan hasil perbandingan terbesar antara tiang sirip dan tiang polos yaitu sebesar 538,75\%. Pengujian tiang sirip berdasarkan fungsi waktu, daya dukung aksial mengalami penurunan pada waktu pengujian 1, 4, 16 hari. Sedangkan daya untuk tiang polos selalu mengalami peningkatan berdasarkan fungsi waktu. Faktor peningkatan daya dukung $(\Delta 10)$ adalah sebesar 0,054 untuk tiang polos dan 0,014 unuk tiang sirip. Faktor peningkatan hasil penelitian ini lebih kecil dari penelitian sebelumnya, hal ini karena tanah yang digunakan tanah lanau organik. Tanah organik memiliki kadar air yang tinggi dan daya dukung yang rendah terhadap beban.

Kata kunci: Pengaruh Waktu, Daya Dukung, Faktor Peningkatan (\$10).
\end{abstract}

\begin{abstract}
This study examines the effect of time on increasing the bearing capacity of fin and plain pile foundations. The variation of testing time in this study was $0,1,2,4,8,16,32$ and 64 days, all variations will be analyzed and compared the results of the axial bearing capacity of the fin and plain pile foundations. The results of this study display the results of the largest comparison between fin piles and plain piles which amounted to $538.75 \%$. Testing of the fin pole based on the function of time, the axial bearing capacity has decreased at the time of testing 1, 4, 16 days. While the power for plain piles always increases based on the function of time. The increasing bearing capacity factor $(\Delta 10)$ is 0.054 for plain piles and 0.014 for fin piles. The improvement factor of the results of this study was smaller than previous studies, this is because the soil used was organic silt. Organic soils have high water content and low carrying capacity for loads.
\end{abstract}

Keywords: Effect of Time, Bearing Capacity, Increasing Factors (410).

\section{PENDAhULUAN}

Fondasi tiang merupakan salah satu bagian dari struktur yang penting karena berfungsi untuk menyalurkan beban dari struktur atas ke dalam lapisan tanah pada kedalaman tertentu. Bahan utama dari tiang adalah kayu, baja (steel), dan beton. Perkembangan desain fondasi tiang pancang telah maju dengan pesat seiring dengan berkembangnya ilmu dan teknologi rancang bangun dalam dunia teknik sipil. Penggunaan Tiang Pancang dalam berbagai konstruksi sipil turut mengalami perbaikan dan penyempurnaan, jenis pondasi ini masih menjadi pilihan yang utama terutama untuk kondisi yang kurang menguntungkan.
Penambahan sirip ulir di sepanjang model fondasi tiang dengan variasi jumlah putaran dan jumlah sirip. Penelitian dilakukan pada tanah silty sand. Hasil penelitian ini menunjukan peningkatan daya dukung fondasi dengan Penambahan sirip ulir dibandingkan dengan pipa polos secara signifikan. Semakin banyak jumlah dan putaran sirip ulir maka daya dukung fondasi akan meningkat.

Rasio dari dari daya dukung fondasi menghasilkan faktor peningkatan $(\Delta 10)$. Penelitian yang sebelumnya yang dilakukan (Liana, 2012) pada tanah lunak, faktor peningkatan $(\Delta 10)$ yang didapatkan adalah 0,2095 (Metode Chin), dan $\Delta 10=0,2204$ (Metode Mazukiewicz). Penelitian ini juga pernah dilakukan oleh para beberapa ahli sebelumnya antara lain Skov and Denver 
(1988), Bullock et al (2005), dan Augustensen (2006).

Pada penelitian tersebut terdapat adanya peningkatan daya dukung tiang sesuai dengan fungsi waktu. Sedangkan perbedaan dari penelitian tersebut terletak pada faktor peningkatan $(\Delta 10)$ yang didapat berdasarkan pengujian yang dilakukan. Penelitian yang telah dilakukan sebelumnya, fondasi tiang tunggal yang polos yang terbuat dari kayu. Pada penelitian ini dilakukan pada Fondasi tiang tunggal bersirip yang terbuat dari beton. Hal ini bertujuan untuk mengetahui perbandingan faktor peningkatan $(\Delta 10)$ dengan penelitian sebelumnya. Waktu pengujian yang dilakukan pada penelitian ini adalah $0,1,2,4,8,16,32$, dan 64 hari, pemilihan waktu pengujian ini bertujuan untuk mengetahui perubahan daya dukung yang dihasilkan fondasi tiang bersirip dan polos. Penelitian model fondasi ini dilakukan pada tanah lunak.

\section{METODE PENELITIAN}

\subsection{Lokasi Penelitian}

Penelitian dilaksanakan di Laboratorium Mekanika Tanah Jurusan Teknik Sipil Universitas Riau.

\subsection{Alat dan Bahan}

Alat dan bahan pengujian yang digunakan pada penelitian ini adalah tanah lunak yang berasal dari Kabupaten Siak. Pada penelitian ini diperlukan berbagai macam alat sebagai penunjang dalam melakukan penelitian. Adapun peralatan yang digunakan adalah sebagai berikut:

1. Satu set alat pembebanan.

2. Model fondasi tiang penampang lingkaran dengan diameter $2,3 \mathrm{~cm}$ dan panjang 100 $\mathrm{cm}$ yang terbuat dari adukan semen dan pasir serta diisi tulangan diameter $8 \mathrm{~mm}$.

3. Alat uji properties tanah:

a. Alat-alat pengujian kadar air

b. Alat-alat pengujian berat volume

c. Alat-alat pengujian liquid limit.

d. Alat-alat pengujian plastic limit

e. Alat-alat pengujian vane shear

4. Satu set bak pengujian (test tank) berukuran panjang $80 \mathrm{~cm}$, lebar $80 \mathrm{~cm}$, tinggi $120 \mathrm{~cm}$ yang dilengkapi portal penahan dengan tinggi $2 \mathrm{~m}$.

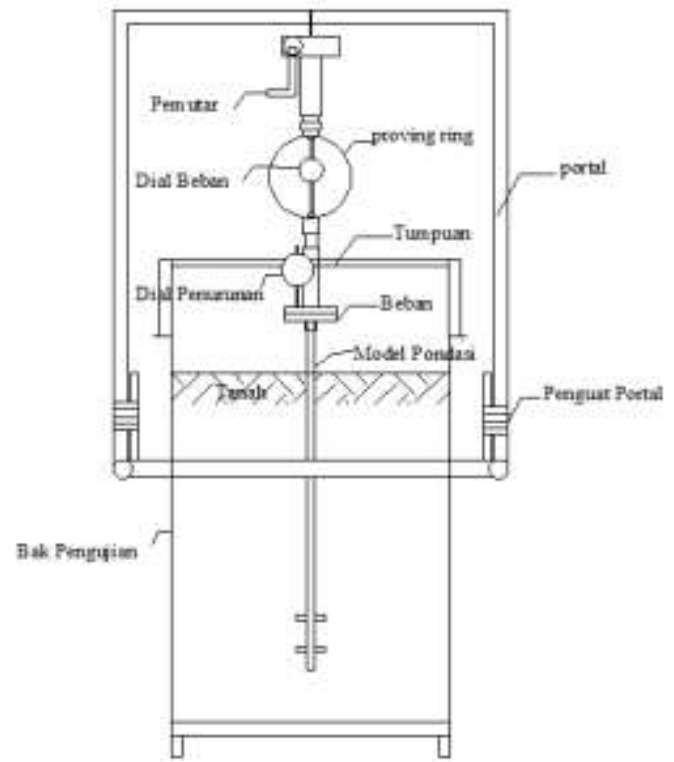

Gambar 1 Bak Pengujian Pembebanan Fondasi Tiang

\subsection{Penamaan dan Jadwal Pengujian Fondasi Tiang}

Pemodelan fondasi tiang pada penelitian ini terdiri dari dua tipe yaitu fondasi tiang sirip dan fondasi tiang polos. Bentuk dan jadwal pengujian dari model fondasi tiang dapat dilihat pada Gambar 2 dan Tabel 1.
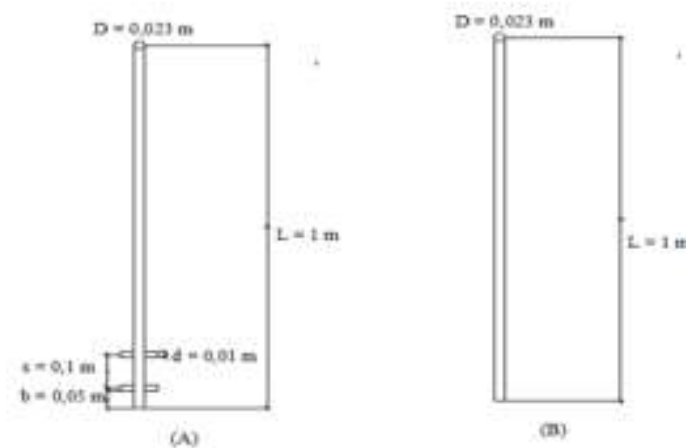

Gambar 1. Model Fondasi Tiang

Tabel 1. Penamaan dan Jadwal Pengujian Fondasi Tiang

\begin{tabular}{ccc}
\hline $\begin{array}{c}\text { Nama } \\
\text { Tiang Sirip }\end{array}$ & $\begin{array}{c}\text { Nama Tiang } \\
\text { Polos }\end{array}$ & $\begin{array}{c}\text { Waktu } \\
\text { Pengujian } \\
\text { (Hari) }\end{array}$ \\
\hline TS0 & TP0 & 0 \\
TS1 & TP1 & 1 \\
TS2 & TP2 & 2 \\
TS4 & TP4 & 4 \\
TS8 & TP8 & 8 \\
TS16 & TP16 & 16 \\
TS32 & TP32 & 32 \\
TS64 & TP64 & 64 \\
\hline
\end{tabular}


Tabel 1 menjelaskan penamaan tiang pancang ,tiang tersebut terdiri dari 2 jenis yaitu Tiang Sirip ( TS) dan fondasi Tiang Polos ( TP), contoh kode penamaan tiang TS0-1 adalah fondasi Tiang Sirip 1 dengan umur Pemancangan 0 hari.

\subsection{Analisis Data}

Data dari hasil penelitian di laboratorium dikumpulkan dan disusun dalam bentuk tabel dan grafik agar mudah untuk di analisis berdasarkan teori dan penelitian yang telah dilakukan, untuk kemudian dapat diambil kesimpulan.

\subsection{Bagan Alir Penelitian}

Berdasarkan dari penelitian yang dilakukan penyusunan laporan tugas akhir ini dapat dijelaskan secara berurutan seperti pada Gambar 3.13.

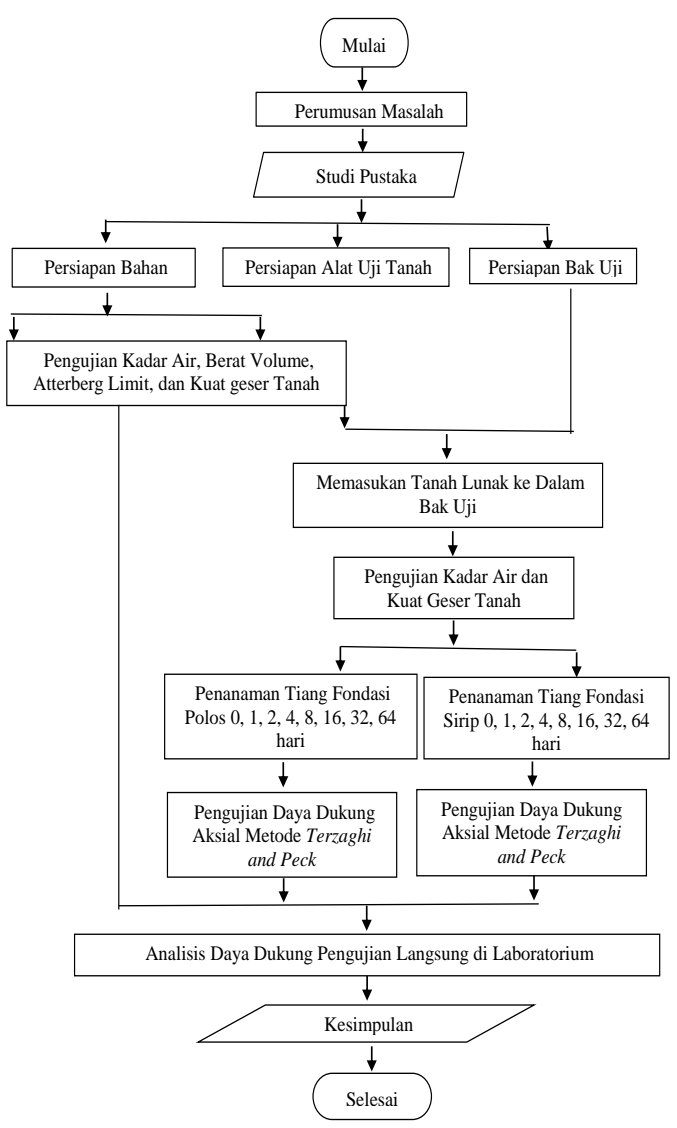

Gambar 3 Bagan Alir Penelitian (Pengujian, 2019)

\section{HASIL dan PEMBAHASAN}

Pada bab ini akan dijelaskan tentang sifat fisik tanah, kadar air dan kuat geser tanah, analisais beban terhadap penurunan, hasil pengujian beban fondasi, dan Pengaruh waktu terhadap daya dukung.

\subsection{Hasil Sifat Fisik dan Propertis Tanah}

Sifat fisik dan propertis tanah yang digunakan dalam penelitian ini diuji terlebih dahulu. Hasil Pengujian sifat fisik dan propertis tanah dapat dilihat pada Tabel 2 .

Tabel 2. Hasil Pengujian Sifat dan Propertis Tanah Lunak

\begin{tabular}{ccc}
\hline $\begin{array}{c}\text { Sifat dan Karasteristik } \\
\text { Tanah Lunak }\end{array}$ & Satuan & Hasil \\
\hline $\begin{array}{l}\text { Kadar Air Rata-Rata } \\
(w)\end{array}$ & $\%$ & 171,69
\end{tabular}

(w)

\begin{tabular}{lcc} 
Spesific Gravity (GS) & - & 2,66 \\
Batas Cair (LL) & $\%$ & 51,00 \\
Batas Plastisitas (PL) & $\%$ & 44,88 \\
Indeks Plastisitas (IP) & $\%$ & 6,12 \\
Kadar Organik & $\%$ & 30,35 \\
Kuat Geser (Su) & $\mathrm{KPa}$ & 5,13 \\
\hline
\end{tabular}

Berdasarkan hasil pengujian sifat dan propertis tanah tersebut, tanah yang digunakan dalam penelitian ini menurut sistem USCS diklasifikasikan sebagai tanah $\mathrm{MH} / \mathrm{OH}$ atau Lanau Organik.

\subsection{Kuat Geser Tanah dan Kadar air}

Pada penelitian ini untuk nilai koreksi baling-baling Vane shear digunakan balingbaling dengan ukuran $16 \times 32 \mathrm{~mm}$ dengan nilai koreksi ke $\mathrm{kPa}=2$ (Arianto, 2010). Hasil dari pengujian kuat geser tanahTabel 4.2 dan Gambar 4.1

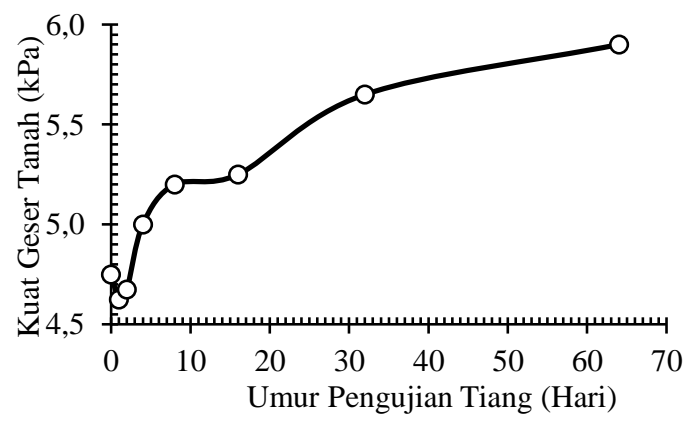

Gambar 4. Hasil Pengujian kuat Geser Tanah 
Gambar 4. menunjukan hasil pengujian kuat geser tanah, nilai Su rata-rata yang didapatkan tidak jauh berbeda dari pengujian umur pemancangan tiang dari 0 hari sampai 64 hari, yaitu berkisar antara 4,75 sampai 5,9 $\mathrm{kPa}$. Hasil pengujian menunjukan bahwa nilai hasil pengujian kuat geser tanah selalu mengalami kenaikan kuat geser.

Pengujian kadar air tanah dilakukan pada setiap hari pengujian tiang, yang bertujuan untuk melihat perubahan dari kadar air selama proses pengujian tiang. Hasil dari pengaruh kadar air dikaitkan dengan perubahan kapasitas daya dukung fondasi selama pengujian umur pemancangan fondasi tiang. Hasil dari pengujian kadar air tanah dapat dilihat dari Gambar 5

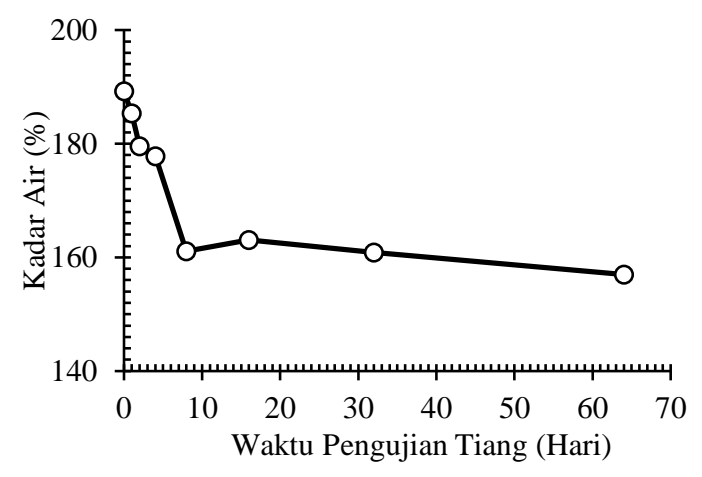

Gambar 5. Hasil Pengujian Kadar Air RataRata

\subsection{Analisis Grafik antara Beban dan Penrunan Fondasi Tiang}

Semua jenis tiang diuji memiliki ukuran yang sama dengan perbedaan jenis pengaruh waktu pemancangan tiang, maka akan menghasikan kekuatan yang berbeda-beda. Setiap pengujian model fondasi tiang sirip dilakukan pada setiap hari pengujian $0,1,2$, 4, 8, 16, 32 dan 64 hari. Hasil pengujian yang dilakukan kemudian digambarkan dengan grafik yang menghubungkan antara gaya beban dan penurunan. Untuk melihat bagaimana pengaruh antara beban dan penurunan yang diakibatkan oleh umur pemancangan tiang maka diambil perbandingan antara 4 jenis pengujian tiang terhadap waktu yaitu TS0, TS4, TS16, TS64. Analisis dari pemodelan jenis tiang fondasi tiang sirip dilihat pada Gambar 6.

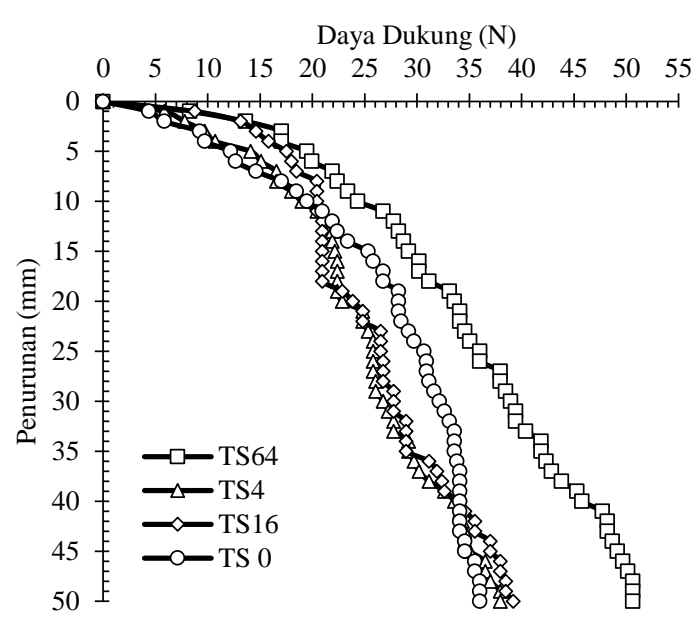

Gambar 6. Hasil Analisis Penggerakan Beban Terhadap Penurunan Pada Fondasi Tiang Sirip

Gambar 6 menjelaskan analisis pergerakan beban terhadap penurunan dengan pembacaaan pergerakan penurunan 0 sampai $50 \mathrm{~mm}$. Tetapi hanya model fondasi dengan umur pemancangan 0 hari (TS0) mengalami pergerakan yang naik dan turun. Beban maksimun yang didapat terjadi pada penurunan $25 \mathrm{~mm}$. sedangkan empat jenis model tiang yang lain TS4, TS316, dan TS64 mendapatkan pergerakan beban selalu mengalami kenaikan. Sehingga nilai beban maksimum yang di dapat oleh 3 tiang tersebut terjadi pada penurunan terakhir yaitu $50 \mathrm{~mm}$. Kesimpulan dari hasil analisis ini adalah Daya dukung fondasi tiang polos pada penurunan $50 \mathrm{~mm}$ dari waktu pengujian 0 sampai 64 hari cenderung mengalami peningkatan. Hal ini disebabkan oleh kenaikan kuat geser tanah selama umur pemancangan tiang.

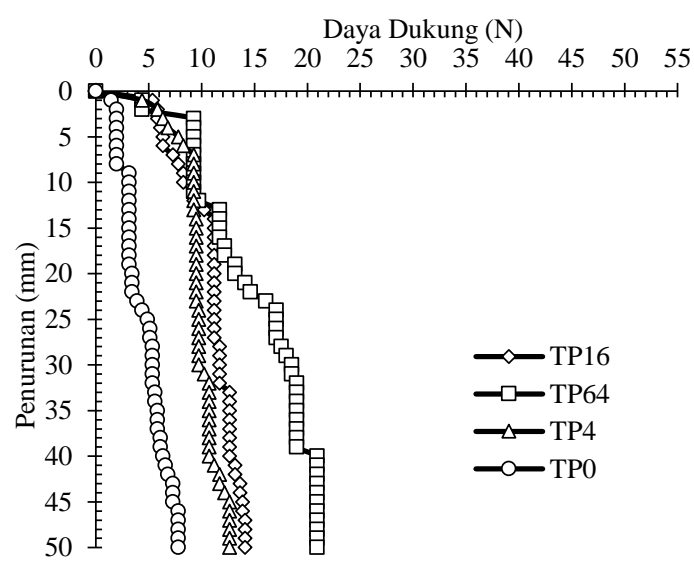

Gambar 7. Hasil Analisis Penggerakan Beban Terhadap Penurunan Pada Fondasi Tiang Polos 
Gambar 7 menjelaskan analisis pergerakan beban terhadap penurunan dengan pembacaaan pergerakan penurunan 0 sampai $50 \mathrm{~mm}$. semua tiang yang diuji selalu mengalami peningkatan beban dalam setiap penetrasi atau penurunan Yang terjadi pada tiang. Kesimpulan dari hasil analisis ini adalah Daya dukung fondasi tiang polos pada penurunan $50 \mathrm{~mm}$ dari waktu pengujian 0 sampai 64 hari selalu mengalami peningkatan. Hal ini disebabkan oleh kenaikan kuat geser tanah selama umur pemancanan tiang.

\subsection{Perbandingan Hasil Pengujian Model Tiang Fondasi}

Hasil pengujian Beban fondasi yang digunakan pada penelitian ini adalah metode Terzaghi and Peck, metode ini merupakan metode penentuan daya dukung ultimate berdasarkan beban yang sesuai denganpenurunan $25 \mathrm{~mm}$ (Q25). Berbagai penelitian yang telah dilakukan sebelumnya menyatakan bahwa metode Terzaghi dan Peck lebih konservatif dibandingkan beberapa metode lainnya.

Hasil perbandingan daya dukung fondasi tiang sirip dan tiang polos dari metode Intrepetasi Terzaghi and Peck akan ditampilkan pada Tabel 4.6 dan Gambar 4.9. Hal ini bertujuan untuk melihat bagaimana pengaruh perubahan daya dukung berdasarkan waktu pengujian antara tiang polos dan tiang sirip.

Tabel 3. Perbandingan Daya Dukung Fondasi Antara Tiang Sirip dan Polos

\begin{tabular}{cccc}
\hline $\begin{array}{c}\text { Pengujian } \\
\begin{array}{c}\text { Tiang } \\
\text { (hari) }\end{array}\end{array}$ & $\begin{array}{c}\text { Tiang } \\
\text { Sirip } \\
(\mathrm{N})\end{array}$ & $\begin{array}{c}\text { Tiang } \\
\text { Polos } \\
(\mathrm{N})\end{array}$ & Perbandingan \\
\hline 0 & 30,7 & 5,8 & $5,29: 1$ \\
1 & 23,7 & 5,9 & $4,02: 1$ \\
2 & 25,4 & 8,8 & $2,89: 1$ \\
4 & 25,3 & 9,7 & $2,61: 1$ \\
8 & 31,2 & 10,2 & $3,09: 1$ \\
16 & 26,5 & 11,1 & $2,39: 1$ \\
32 & 38,0 & 15,6 & $2,44: 1$ \\
64 & 36,0 & 17,0 & $2,12: 1$ \\
\hline
\end{tabular}

Gambar 8. Grafik Hasil Perbandingan Daya Dukung Fondasi Antara Tiang Sirip dan Polos.

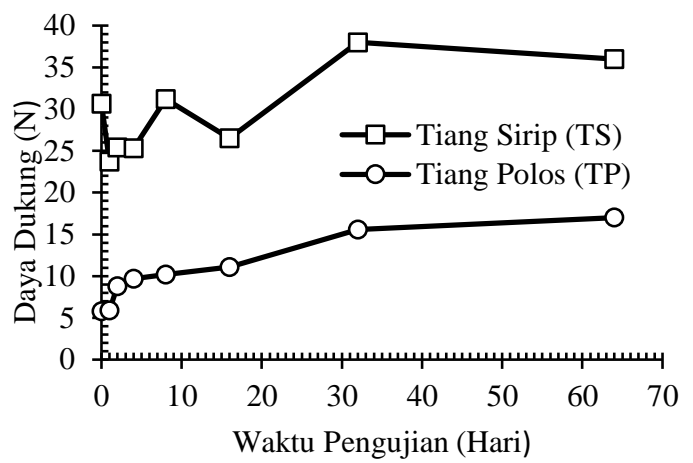

Gambar 4.9 Grafik Hasil Perbandingan Daya

Dukung Fondasi Antara Tiang Sirip dan

Polos

Tabel 3 dan Gambar 8 memperlihatkan daya dukung fondasi sirip jauh lebih besar dari fondasi tiang polos, hal ini karena penambahan sirip mampu menambah kekuatan tahanan fondasi terhadap beban pada tanah lunak.

\subsection{Pengaruh Waktu Terhadap Peningkatan Kapasitas Daya Dukung}

Daya dukung ultimate (Qult) dari hasil penelitian ini telah didapatkan dengan cara analisis dari pengujian di lapangan metode Terzaghi and Peck (1967). Terdapat empat jenis tiang yang di uji dengan Variasi waktu 0, $1,2,4,8,16,32$ dan 64 hari, hasil dari analisis pengaruh waktu terhadap kapasitas daya dukung fondasi dijelaskan dengan metode berikut.

\subsubsection{Kapasitas Daya Dukung Aksial Referensi $\left(Q_{0}\right)$}

Kapasitas daya dukung referensi pada fondasi tiang ditentukan berdasarkan regresi linier dengan menggunakan grafik semi log pada Gambar 10

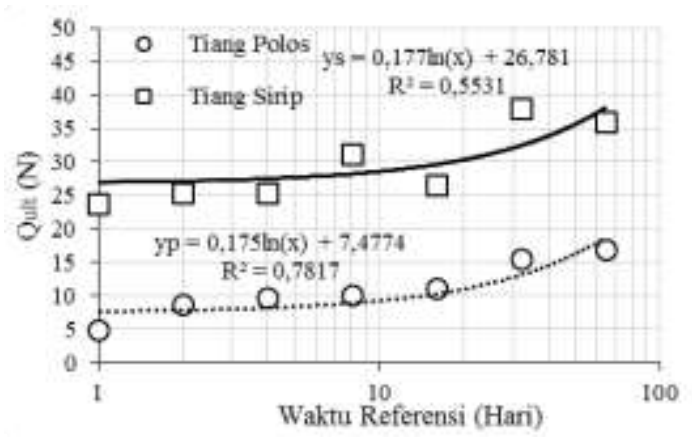

Gambar 10. Hubungan Antara Qult metode Terzaghi dengan waktu referensi $\left(t_{0}\right)$ 
dengan $t_{0}$ (waktu referensi) pada Gambar 4.11 Diperoleh kapasitas daya dukung referensi $\left(Q_{0}\right)$ pada fondasi tiang siripdan tiang polos dengan persamaan berikut.

$\mathrm{Q}_{0}$ Tiang Polos

ys $=0,177 \cdot \ln (\mathrm{x})+26,781 \mathrm{~N}$ dengan nilai

xs $\left(t_{0}\right)=1$ hari,

$\left(Q_{0}\right)=\mathrm{ys}=0,177 \cdot \ln (1)+26,781=26,958 \mathrm{~N}$

$\mathrm{Q}_{0}$ Tiang Polos

$0,175 \cdot \ln (\mathrm{x})+7,477$ dengan nilai $\mathrm{xp}\left(t_{0}\right)=1$ hari,

$\left(Q_{0}\right)=\mathrm{yp}=0,175 \cdot \ln (1)+7,477=7,477 \mathrm{~N}$

\subsubsection{Rasio Kapasitas Daya Dukung Referensi $\left(\boldsymbol{r}_{t}\right)$}

Rasio kapasitas daya dukung referensi adalah perbandingan nilai (Qult) dengan kapasitas aksial referensi Q0

Tabel 4 Nilai Rasio Qult Terhadap Q0

\begin{tabular}{cccc}
\hline $\begin{array}{c}\text { Jenis } \\
\text { Fondasi } \\
\text { Tiang }\end{array}$ & Rasio & $\begin{array}{c}\text { Jenis } \\
\text { Fondasi } \\
\text { Tiang }\end{array}$ & Rasio \\
\hline TS0 & 1,14 & TP0 & 0,64 \\
TS1 & 0,88 & TP1 & 0,66 \\
TS2 & 0,95 & TP2 & 1,18 \\
TS 4 & 0,94 & TS 4 & 1,30 \\
TS 8 & 1,17 & TS 8 & 1,36 \\
TS 16 & 0,99 & TS 16 & 1,48 \\
TS 32 & 1,42 & TS 32 & 2,09 \\
TS 64 & 1,34 & TS 64 & 2,27 \\
\hline
\end{tabular}

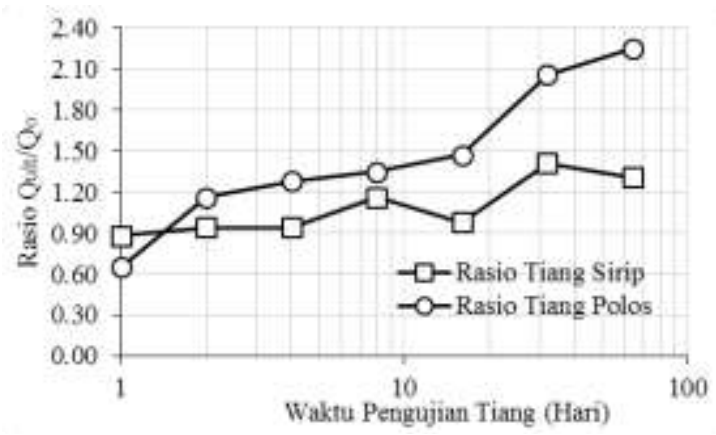

Gambar 11 Hubungan Rasio Antara Qult metode Terzaghi dan Q 0 berdasarkan waktu referensi
Gambar 11 menjelaskan rasio daya dukung fondasi tiang polos lebih besar dibandingkan rasio daya dukung fondasi tiang sirip. Hal ini disebabkan oleh selisih peningkatan daya dukung setiap waktu pengujian. Pada grafik tiang sirip terjadi penurunan rasio karena pada saat pengujian 16 hari ke 32 hari daya dukung fondasi mengalami penurunan.

\subsection{Pengaruh Perbandingan Waktu Terhadap Daya Dukung Aksial Fondasi}

Perbandingan pengaruh waktu terhadap dari dukung fondasi yang diperoleh dari penelitian Skov dan Denver, (1998), Bullock en al. (2005), Augustesen el al. (2006), dan perbandingan fondasi tiang sirip dan polos metode Terzaghi and Peck. Maka dibuatlah grafik semilog hasil dari pembahasan dari penelitian, berdasarkan hubungan rasio waktu pengujian tiang (Qult) dan waktu referensi tiang $\left(\mathrm{Q}_{0}\right)$ pada Gambar 4.13.

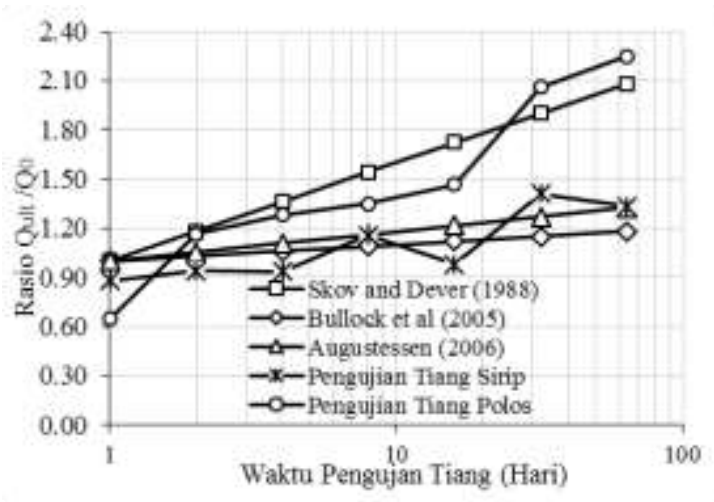

Gambar 12 Perbandingan Antara Rasio Metode Terzaghi Dengan beberapa Penelitian Sebelumnya

Gambar 12 menjelaskan garis pengaruh waktu terhadap kapasitas daya dukung aksial fondasi, yaitu grafik pemgujian 3 peneliti sebelumnya berbentuk linier. Pada penelitian dengan metode Terzaghi and Peck pada tiang polos grafik rasio tidak linier seperti 3 penelitian sebelumnya, tetapi pergerakan grafik terhadap rasio daya dukung terhadap waktu selalu mengalami peningkatan. Pada penelitian tiang sirip grafiknya tidak beraturan dan mengalami peningkatan dan penurunan rasio daya dukung terhadap waktu. Hal ini karena proses pemulihan tanah yang rusak akibat pemancangan tiang fondasi sirip (Recovery) tidak merata. Proses ini mengakibatkan pergerakan beban pada 
fondasi pada penurunan $25 \mathrm{~mm}$ tidak beraturan.

\subsection{Penentuan Faktor Peningkatan $(\Delta 10)$}

Peningkatan $(\Delta 10)$ adalah faktor yang menunjukan pengaruh waktu terhadap peningkatan kapasitas dukung aksial pada pondasi tiang tunggal. Pada penelitian ini hasil dari faktor peningkatan ditentukan oleh hasil regresi rasio kapasitas daya dukung berdasarkan grafik logaritmik. Skov and Denver (1988) merumuskan Qult / Q $0=r_{t}$, Maka diambil persamaan sebagai berikut.

$$
\Delta 10=\left(r_{t}-1\right) / \log 10\left(\frac{\mathrm{t}}{\mathrm{t}_{0}}\right)
$$

Berdasarkan persamaan diatas hasil faktor peningkatan $(\Delta 10)$ dari penelitian ini adalah 0,054 untuk model fondasi tiang bersirip dan 0,014 untuk model fondasi tiang polos. Dengan demikian, hasil $(\Delta 10)$ dari penelitian ini lebih kecil dibandingkan hasil penelitian dari para ahli sebelumnya.

\section{KESIMPULAN dan SARAN}

\subsection{Kesimpulan}

1. Pengujian static loading dengan menggunakan metode CRP Test. Hasil uji pembebanan fondasi tiang bersirip lebih besar dari tiang polos.

2. Pada pengujian tiang sirip metode Terzaghi and Peck, kapasitas daya dukung berdasarkan fungsi waktu mengalami naik dan turun. Daya dukung terbesar terjadi pada waktu pengujian fondasi tiang 32 hari (TS32) sebesar 38,0 $\mathrm{N}$, sedangkan daya dukung terkecil terjadi pada waktu pengujian fondasi tiang 1 hari (TS1) yaitu sebesar 23,7 N. Kapasitas daya dukung pada fondasi polos mengalami kenaikan dalam setiap pengujian terhadap waktu. Peningkatan terbesar terjadi pada waktu pengujian 64 hari (TP64) sebesar 17,0 N. Sedangkan dukung fondasi tiang polos terjadi pada pengujian 0 hari yaitu sebesar 5,8 N

3. Perbandingan daya dukung terbesar antara fondasi tiang sirip dan polos terjadi pada 4. pada waktu pemgujian 0 hari yaitu sebesar $538,75 \%$, sedangkan perbandingan daya dukung terendah terjadi pada pengujian 64 hari yaitu sebesar $211,76 \%$

4. Besar peningkatan $(\Delta 10)$ berdasarkan pengaruh waktu terhadap daya dukung metode Terzaghi dan Peck sebesar 0,014 untuk tiang sirip dan 0,054 untuk tiang polos. Hasil faktor peningkatan $(\Delta 10)$ penelitian ini lebih kecil dibandingkan hasil penelitian sebelumnya, hal ini terjadi karena jenis tanah yang dipakai untuk pengujian pembebanan fondasi mempunyai kemampuan daya dukung yang rendah.

\subsection{Saran}

1. Untuk pengujian pembebanan aksial pada fondasi dengan metode CRP, sebaiknya rangka portal diberi penahan yang kaku untuk portal, agar portal tidak goyang, apabila portal goyang sedikit saja akan mengganggu hasil dari pembebanan fondasi.

2. Sampel tanah didalam bak harus diletakan diruangan yang tertutup dan jauh dari sinar matahari. Agar kuat geser dan Kadar air tanah tidak mengalami perubahan yang signifikan.

3. Sampel tanah harus diberi air secara rutin dan ditutup dengan kain basah, agar tidak terjadi penguapan.

\section{Daftar Pustaka}

[1] Arianto Tjatur. 2010. Studi Kuat Geser Tanah Lunak dengan Metode Uji Geser Sudu Lapangan dan Uji Geser Sudut Laboratorium. Fakultas Teknik Universita Indonesia, Depok

[2] ASTM D1143-81. 1994. Standard Test Method For Piles Under Static Axial Compressive Load. United States of America: Annual Book of ASTM Standards sec 4.

[3] ASTM D2573-01. 2001. Standard Test Method For Field Vane Shear Test in Cohesive Soil. United States of America: Annual Book of ASTM Standards sec 4.

[4] ASTM D2974-00. 2000. Standard Test Method For Moisture, Ash, and Organic Matter of Peat and Other Organic Soils. United States of America: Annual Book of ASTM Standards sec 4. 
[5] Bestarivo Anggun (2010). Disain Perencanaan Tiang pancang Siriv dan Metode Pemancangannya. Universitas Putera Indonesia "YPTK", Padang.

[6] Das, B.M., 2006. Principles of Geotechnical Engineering 5th ed. P. Daly, ed., Toronto, Kanada: Chris Carson.

[7] Hardiyatmo, Hary Christady. 2002. Teknik Fondasi I. Yogyakarta: Gadjah Mada University Press.

[8] Hardiyatmo, Hary Christady. 2006. Mekanika Tanah I. Yogyakarta: Gadjah Mada University Press.

[9] Hery Christady, H. 2008. Rekayasa Pondasi II. Fakultas Teknik Universitas Gajah Mada, Yogyakarta: Beta Offset. Vol; 4 ..

[10] Kesuma, I Dewa Gede Mas Jaya. 2011. Uji Kapasitas Tarik Model Tiang Sirip Pada Tanah Pasir. Yogyakarta.

[11]Liana. 2012. Pengaruh Waktu Terhadap Peningkatan Kapasitas Aksial pondasi Tiang tunggal Pada Tanah Lunak. Fakultas Teknik Universitas Riau, Pekanbaru.

[12] Nurdin Sukirman. 2011. Analisis Perubahan Kadar Air dan Kuat Geser Tanah Gambut Lalombi Akibat Pengaruh Temperatur dan Waktu Pemanasan. Jurnal SMARTek, vol. 9, No. 2: $88-108$.

[13] Sakr Mohammed. (2010). Lateral Resistance of High Capacity Helical Piles - Case Study. Almita Manufacturing Ltd. Ponaka, Alberta, Canada.

[14] Suyadi, et al. 2014. Peningkatan Daya Dukung Pondasi Tiang Dengan Penambahan Sirip Ulir Menggunakan Pendekatan Rumus Empiris dan Model Test. 8(1), 65-70.

[15]Wardana, Razaq A.C, 2012. Pengaruh Waktu Terhadap Peningkatan Kapasitas Dukung Kelompok Tiang Pada Tanah Lunak. Fakultas Teknik Universitas Riau, Pekanbaru. 